\title{
Detecting Substance Abuse in the Emergency Department: A 10-Year Comparative Study
}

\author{
Fernando Espi Martinez, ${ }^{1}$ Joaquin Nieto Munuera, ${ }^{1}$ \\ Jose Antonio Noguera Velasco, ${ }^{2}$ and Fernando Espi Forcen ${ }^{3}$ \\ ${ }^{1}$ Facultad de Medicina, Universidad de Murcia, Campus de Espinardo, 30100 Murcia, Spain \\ ${ }^{2}$ Hospital Virgen de La Arrixaca, Carretera de Cartagena s.n., El Palmar, 30120 Murcia, Spain \\ ${ }^{3} 5841$ S. Maryland, MC3077, The University of Chicago, IL 60637, USA \\ Correspondence should be addressed to Fernando Espi Forcen; ferespi@hotmail.com
}

Received 19 June 2013; Accepted 14 August 2013

Academic Editors: S. Di Saverio, L. V. Downey, and M. Mohsin

Copyright (C) 2013 Fernando Espi Martinez et al. This is an open access article distributed under the Creative Commons Attribution License, which permits unrestricted use, distribution, and reproduction in any medium, provided the original work is properly cited.

\begin{abstract}
Aims. We have retrospectively analyzed the variations in the clinical profile of patients with a positive consumption of alcohol and/or drugs of abuse that have been confirmed and treated in the Emergency Department of a Virgen de La Arrixaca University Hospital in Murcia (Spain) after a period of 10 years. Secondly, we have assessed if the use of urine toxicology screen tests had any influence on the improvement of the management and/or referral of these patients to specialized services from the Emergency Department or at the time of discharge from hospital, regardless of the specialist or service where they had been treated. Method. 415 patients were selected in the year 2000 and 452 in the year 2010 who had tested positive for alcohol and drugs, assessing the reason for consultation, specific symptoms, drug used, record, diagnosis, and patient management. Results. The most frequent reasons for going to the Emergency Department was common illness, mainly psychiatric disorders, and the type of drug taken, alcohol. There were no significant differences between both groups, but approximately $50 \%$ of the patients were not referred for treatment of the abuse or dependency. Conclusions. The clinical profession should consider measures to improve detection and referral of patients with substance abuse disorders.
\end{abstract}

\section{Introduction}

The consumption of alcohol and drugs of abuse in the Health Services is a frequent problem, but often it is not diagnosed. The abusive consumption of alcohol, anxiolytics and illegal, may lead to demand for direct medical care (intoxication, overdose, or withdrawal), and above all, a high demand for indirect medical care (medical or psychiatric complications). Prevalence of substance abuse disorders is higher in population treated in Healthcare Facilities than in the general population. According to some studies, between patients treated 4 and $40 \%$ may show signs of consuming some kind of toxic substance excluding tobacco [1-4].

The abusive consumption of alcohol may reach up to $17 \%$ of the adult population seen at the Primary Healthcare Centers [5] and $13.9 \%$ of the patients admitted to Hospitals [6]. In the Emergency Department (ED), the problems related with the consumption of alcohol and drugs can be even higher $[7,8]$. The variety of doctors taking part in these services to deal with these complications, the reluctance of patients to admit their consumption, could be barriers to diagnosis, referral, and treatment to specialized substance abuse units.

Screening tests to determine levels of alcohol or the presence of drugs of abuse in blood and urine are commonly used with diagnostic purposes, especially when it is suspected that the patient's symptoms or the reason for admission is connected with the admission. However, these tests have their limitations: some determinations are qualitative: they may not be helpful to distinguish between acute and chronic uses, they may be prescribed by the doctor, and their results may not influence over the therapeutic management of the patient [9]. Studies done in EDs have been carried out prospectively over a short period of time, probably due to the large number of patients, and, above all, most of them are focused 
on specific populations [4]. Variation of symptoms with the type of consumption and doctor's interest in ordering urine toxicology may be barriers to diagnosis of substance abuse. However, the routine introduction of toxicological tests in hospital EDs has facilitated the diagnosis of this consumption in patients treated for indirect reasons that were not recognized in their medical records. These tests should alert doctors to detect pathological consumers for a more efficient treatment, beyond medical complications. Data highlight the importance of making an early diagnosis and intervention to reduce the number of patients with alcohol abuse and other drugs of abuse [3].

In our study, we have analyzed the clinical changes in patients treated in the hospital ED with alcohol and drug consumption and their referral to specialized services after 10 years. For that, several patterns have been explored such as registration details, symptoms at admission, psychiatric history, and clinical management.

\section{Material and Methods}

The study was carried out at a third-level University Hospital covering a population of 250,000 , with an average number of 100,000 patients seen at the General Emergency Department per year, and which also has an Addictive Behavior Unit. The study was approved by the hospital's Ethics Committee. During a period of 24 months (January to December of the years 2000 and 2010), and, retrospectively, all the medical records of the General ED were studied where there had been positive testings for blood or urine of alcohol and drugs of abuse such as cannabis (11 nor-D 9-tetrahydrocannabinol or THC) benzoylecgonine, opiates, methadone, amphetamines and derivatives, and benzodiazepines (BZD).

The Toxicology Department had been created in 1997. Our intention was to compare the patterns of substance abuse and referral after 10 years to explore if there were significant differences in the way clinicians had approached this problem.

A total of 906 medical records were collected, from which 867 were selected as they had a history of toxic abuse at the time of arrival to the Emergency Department. 4\% (39) of the medical records were excluded, because the drug abuse detected was not the trigger for the reason for admission, and they were drugs appropriately prescribed by the doctor: BZD, opiates, and methadone.

Out the total number of patients, 415 were selected in the year 2000 and 452 in 2010, respectively. By means of a data collection protocol the following were recorded: (1) registration details: age, sex, day and time of arrival, care unit, origin, and final destination. (2) Symptoms of admission: relation with consumption; reason of consultation: common illness, casual accident, aggression, traffic accident, or attempted suicide; and, finally, specific symptoms: psychiatric ones such as behavioral changes, confusion, agitation, aggressiveness, anxiety, psychosis and/or delirium, and level of attempted suicide; neurological ones such as alteration and/or reduction in level of consciousness, neurological focality, headache, and convulsive crisis; finally, others such as chest pain, trauma, hypertensive crisis, and various others. (3) Psychiatric record with or without treatment, record of unhealthy use of alcohol or drugs of abuse and psychiatric diagnosis. (4) Additional tests: toxic levels in blood and urine, general and specific blood tests, radiological tests, and other additional tests for diagnosis. (5) Clinical management: definitive diagnosis, hospital discharge, or admission and referral to a unit specializing in drugs of abuse or Mental Health Center.

The presence in urine of cannabis, cocaine (benzoylecgonine), methadone and other opiates (heroin, morphine), and amphetamines was determined by CEDIA enzyme immunoassay in a Siemens DIMENSION analyzer, using conventional cutoff values $(200,50,300,300,300 \mathrm{ng} / \mathrm{mL}$, resp.). Ethanol was determined by $\mathrm{ADH}$ enzymatic assay in the same analyzer. To confirm the presence of some toxics, urine was analyzed by high resolution liquid chromatography (HPLC), Remedi, Biorad.

The statistical processing of the data was done using the SPSS-19 program. The qualitative variables have been expressed in the form of percentage and absolute number (Chi-square test and fisher's exact test).

\section{Results}

3.1. Registration Details. The two groups corresponding to the years 2000 and 2010 did not show significant differences in frequency: $47.9 \%$ (415) versus $52.1 \%$ (452); sex: $74 \%$ (307) male and 26\% (108) female versus 69.2\% (313) male and 30.8\% (139) female; and average age: 34.5 (SD 13.88) versus 38.91 (SD 15.9).

The tendency to turn up more frequently at weekends was maintained in both groups, perhaps with a higher redistribution on other days of the week for the 2010 group. The time of arrival to the ED between 12 midnight and 4 am was significantly higher in the 2010 group: 12\% (104) versus the 2000 group: $7.8 \%$ (68) unlike the period between $8 \mathrm{pm}$ and 12 midnight, significantly lower in the 2010 group: $9.2 \%$ (80) versus the 2000 group: $13.6 \%$ (118) (Table 1).

As a whole, arrival to the Emergency Department was in $48.5 \%$ (420) of the cases by an emergency system (ambulance, police), $26.7 \%$ (232) were sent by friends and relatives, and $4.4 \%$ (38) were referred from other healthcare facilities; the remaining $20.4 \%$ (177) turned up on their own initiative. The initial care was provided at the Psychiatric Unit in 36.5\% (316) of the cases, $36.3 \%$ (315) at the Internal Medicine Unit, and $22.3 \%$ (193) at the Surgery or Trauma Units. $4.8 \%$ of patients (42) were directly treated in the Intensive Care Unit (ICU) due to the seriousness of their condition.

3.2. Symptoms of Admission. When comparing the reasons for admission to the Emergency Department for both groups (Table 2), we have found significant differences, with a rise in common illness: $23.2 \%$ (202) versus $28.2 \%$ (247) and attempted suicide: $9.3 \%$ (81) versus $11.5 \%$ (100) and fewer traffic accidents: $7.3 \%$ (63) versus 3.3\% (29). No significant differences were found for casual accident and aggression.

The percentage of patients admitted to hospital fell slightly in the year 2010, with $10.4 \%$ (90) compared to the year 2000 with $13.5 \%$ (117), mainly at the expense of patients 
TABle 1: (a) Years, days, (b) hour interval.

(a)

\begin{tabular}{lcccccccc}
\hline \multirow{2}{*}{ Chi-square: 0.021} & & \multicolumn{3}{c}{ Days } & \multicolumn{2}{c}{ Total } \\
& Sunday & Thursday & Monday & Tuesday & Wednesday & Saturday & Friday \\
\hline \multirow{2}{*}{2000} & 78 & 56 & 62 & 37 & 33 & 83 & 66 & 415 \\
& $18.8 \%$ & $13.5 \%$ & $14.9 \%$ & $8.9 \%$ & $8.0 \%$ & $20.0 \%$ & $15.9 \%$ & $100.0 \%$ \\
\hline \multirow{2}{*}{2010} & 85 & 57 & 53 & 45 & 66 & 65 & 81 & 452 \\
& $18.8 \%$ & $12.6 \%$ & $11.7 \%$ & $10.0 \%$ & $14.6 \%$ & $14.4 \%$ & $17.9 \%$ & $100.0 \%$ \\
\hline
\end{tabular}

(b)

\begin{tabular}{|c|c|c|c|c|c|c|c|}
\hline \multirow{2}{*}{ Chi-square: 0.000} & \multicolumn{6}{|c|}{ Hour interval } & \multirow{2}{*}{ Total } \\
\hline & $0-4 \mathrm{~h}$ & $4-8 \mathrm{~h}$ & $8-12 \mathrm{~h}$ & $12-16 \mathrm{~h}$ & $16-20 \mathrm{~h}$ & $20-24 \mathrm{~h}$ & \\
\hline \multirow{2}{*}{2000} & 68 & 44 & 34 & 69 & 82 & 118 & 415 \\
\hline & $16.4 \%$ & $10.6 \%$ & $8.2 \%$ & $16.6 \%$ & $19.8 \%$ & $28.4 \%$ & $100.0 \%$ \\
\hline \multirow{2}{*}{2010} & 104 & 39 & 69 & 79 & 81 & 80 & 452 \\
\hline & $23.0 \%$ & $8.6 \%$ & $15.3 \%$ & $17.5 \%$ & $17.9 \%$ & $17.7 \%$ & $100.0 \%$ \\
\hline
\end{tabular}

TABLE 2: (a) Reason for consult, (b) admissions.

(a)

\begin{tabular}{|c|c|c|c|c|c|c|}
\hline \multirow{2}{*}{ Chi-square: 0.001} & \multicolumn{5}{|c|}{ Reason for consult } & \multirow{2}{*}{ Total } \\
\hline & Accident (nontraffic) & Aggression & Self-harm & Common illness & Traffic accident & \\
\hline \multirow{2}{*}{2000} & 51 & 18 & 81 & 202 & 63 & 415 \\
\hline & $12.3 \%$ & $4.3 \%$ & $19.5 \%$ & $48.7 \%$ & $15.2 \%$ & $100.0 \%$ \\
\hline \multirow{2}{*}{2010} & 51 & 25 & 100 & 247 & 29 & 452 \\
\hline & $11.3 \%$ & $5.5 \%$ & $22.1 \%$ & $54.6 \%$ & $6.4 \%$ & $100.0 \%$ \\
\hline
\end{tabular}

(b)

\begin{tabular}{lccc}
\hline Chi-square: 0.004 & 2000 & 2010 & Total \\
\hline Admissions & & & 660 \\
NO & 298 & 362 & $100.0 \%$ \\
& $45.2 \%$ & $54.8 \%$ & 207 \\
SI & 117 & 90 & $100.0 \%$ \\
\hline
\end{tabular}

admitted to the ICU. The Psychiatric Unit was the one admitting most patients (Table 2).

The specific symptoms registered in the ED record (Table 3) were grouped into psychiatric symptoms, neurological symptoms, and symptoms of other organs or systems. All these symptoms varied in frequency between the years 2000 and 2010, but the differences were not significant, with the exception of psychiatric symptoms that decreased in 2010.

If we relate specific symptoms to reasons for admission, we note that patients arriving due to common illness or attempted suicide do so frequently accompanied by psychiatric symptoms and, to a lesser extent, neurological ones and above all a reduction in the level of consciousness, while the rest of reasons are due to other symptoms, mainly trauma and, among the latter, TBI.

3.3. Psychiatric Record and Diagnosis. We have not observed significant differences in frequency between patients with a psychiatric record (including drug abuse), exclusive records of drug abuse, and psychiatric diagnosis for the 2000 group: $28.3 \%$ (246), $23.7 \%$ (206), and $29.4 \%$ (255) versus the 2010 group: $31.8 \%$ (276), $22.2 \%$ (193), and 33.3\% (289), respectively (Table 4).

When relating attempted suicide with associated psychiatric diagnosis, we found that the mixed anxiety-depressive syndrome and abusive consumption of alcohol and other drugs were the most frequent, depression and personality disorders with an average frequency, and others such as dementia, schizophrenia, food behavior disorder, mental retardation, and obsessive-compulsive disorder, infrequent. We did not find significant differences between these three subgroups regarding the years 2000 and 2010.

3.4. Additional Tests. The types of drugs most frequently consumed in both groups were alcohol, BZD, and cocaine.

If we compare drug abuse by year we find significant differences in alcohol, BZD, THC, and methadone but not in opiates, amphetamines, and cocaine. 
TABle 3: (a) Psychiatric symptoms, (b) neurological symptoms, and (c) other symptoms.

(a)

\begin{tabular}{cccc}
\hline Chi-square: 0.001 & 2000 & 2010 & Total \\
\hline Psychiatric symptoms & & & \\
NO & 174 & 239 & 413 \\
& $42.1 \%$ & $57.9 \%$ & $100.0 \%$ \\
\multirow{2}{*}{ SI } & 241 & 213 & 454 \\
& $53.1 \%$ & $46.9 \%$ & $100.0 \%$ \\
\hline
\end{tabular}

(b)

\begin{tabular}{lccc}
\hline Chi-square: 0.146 & 2000 & 2010 & Total \\
\hline Neurological symptoms & & & \\
NO & 257 & 258 & 515 \\
& $49.9 \%$ & $50.1 \%$ & $100.0 \%$ \\
SI & 158 & 194 & 352 \\
& $44.9 \%$ & $55.1 \%$ & $100.0 \%$ \\
\hline
\end{tabular}

(c)

\begin{tabular}{lccc}
\hline Chi-square: 0.080 & 2000 & 2010 & Total \\
\hline Other symptoms & & & \\
\multirow{2}{*}{ NO } & 216 & 262 & 478 \\
& $45.2 \%$ & $54.8 \%$ & $100.0 \%$ \\
SI & 199 & 190 & 389 \\
& $51.2 \%$ & $48.8 \%$ & $100.0 \%$ \\
\hline
\end{tabular}

TABle 4: (a) Psychiatric history, (b) drug history, (C) psychiatric diagnosis.

(a)

\begin{tabular}{|c|c|c|c|}
\hline Chi-square: 0.592 & 2000 & 2010 & Total \\
\hline \multicolumn{4}{|l|}{ Psychiatric history } \\
\hline \multirow{2}{*}{ NO } & 169 & 176 & 345 \\
\hline & $49.0 \%$ & $51.0 \%$ & $100.0 \%$ \\
\hline \multirow{2}{*}{ SI } & 246 & 276 & 522 \\
\hline & $47.1 \%$ & $52.9 \%$ & $100.0 \%$ \\
\hline
\end{tabular}

(b)

\begin{tabular}{|c|c|c|c|}
\hline Chi-square: 0.041 & 2000 & 2010 & Total \\
\hline \multicolumn{4}{|l|}{ Drug history } \\
\hline \multirow{2}{*}{ NO } & 209 & 259 & 468 \\
\hline & $44.7 \%$ & $55.3 \%$ & $100.0 \%$ \\
\hline \multirow{2}{*}{ SI } & 206 & 193 & 399 \\
\hline & $51.6 \%$ & $48.4 \%$ & $100.0 \%$ \\
\hline \multicolumn{4}{|c|}{ (c) } \\
\hline Chi-square: 0.448 & 2000 & 2010 & Total \\
\hline \multicolumn{4}{|c|}{ Psychiatric diagnosis } \\
\hline \multirow{2}{*}{$\mathrm{NO}$} & 160 & 163 & 323 \\
\hline & $49.5 \%$ & $50.5 \%$ & $100.0 \%$ \\
\hline \multirow{2}{*}{ SI } & 255 & 289 & 544 \\
\hline & $46.9 \%$ & $53.1 \%$ & $100.0 \%$ \\
\hline
\end{tabular}

TABLE 5: Type of drug.

(a)

\begin{tabular}{cccc}
\hline & 2000 & 2010 & Total \\
\hline Chi-square: 0.039 & & & \\
Alcohol & 284 & 279 & 563 \\
Chi-square: 0.000 & $68.4 \%$ & $61.7 \%$ & $64.9 \%$ \\
BZD & 103 & 203 & 306 \\
Chi-square: 0.000 & $24.8 \%$ & $44.9 \%$ & $35.3 \%$ \\
THC & 26 & 75 & 101 \\
Chi-square: 0.693 & $6.3 \%$ & $16.6 \%$ & $11.6 \%$ \\
Opiates & 39 & 39 & 78 \\
Chi-square: 0.040 & $9.4 \%$ & $8.6 \%$ & $9.0 \%$ \\
Methadone & 12 & & \\
Chi-square: 0.106 & $2.9 \%$ & $5.8 \%$ & $4.4 \%$ \\
Anphetamines & 15 & $26 \%$ & 42 \\
Chi-square: 0.297 & $3.6 \%$ & $6.0 \%$ & $4.8 \%$ \\
Cocaine & & & 178 \\
\hline
\end{tabular}

(b)

\begin{tabular}{cccc}
\hline & THC and alcohol (Chi-square: 0.001$)$ & \\
Alcohol & Year 2000 & Year 2010 & Total \\
\hline \multirow{2}{*}{ s THC s } & 7 & 19 & 26 \\
& $2.5 \%$ & $6.8 \%$ & $4.6 \%$
\end{tabular}

Alcohol and BZD (Chi-square: 0.000)

$$
\begin{array}{cccc}
\text { s Benzos s } & 33 & 66 & 99 \\
& 11.6 \% & 23.7 \% & 17.6 \%
\end{array}
$$

Alcohol and cocaine (Chi-square: 0.005)

\begin{tabular}{cccc} 
s Cocaine s & 33 & 48 & 81 \\
& $11.6 \%$ & $17.2 \%$ & $14.4 \%$ \\
\hline
\end{tabular}

In 2010 consumption of BZD, THC and methadone rose sharply and significantly and that of alcohol fell (Table 5).

No quantitative differences of blood alcohol level were found between both groups (178.8 $\mathrm{mg}$ versus $165.6 \mathrm{mg}$ ), but levels were notably higher in males: $180 \mathrm{mg} \%$ in comparison to females: $147.6 \mathrm{mg} \% .40 \%$ (348) of all patients showed positive for two or more drugs of abuse. In the year 2010, a considerable rise in the tendency to combine two or more drugs was also observed, the most significant combinations being alcohol and BZD (0.000), alcohol and cocaine (0.005), and alcohol and THC (0.001) (Table 5). Half of methadone users also consumed opiates. The abusive intake of BZD alone or associated with alcohol was related to attempted suicide and was notably higher (0.005) in 2010: $43.6 \%$ (79) than in 2000: $34.8 \%$ (63). Other forms of attempted suicide such as the association of other medicines, drugs, toxic substances, or 
TABLE 6: Reason for consult. Referral (Chi-square: 0.001).

\begin{tabular}{|c|c|c|c|c|c|c|}
\hline \multirow{2}{*}{ Referral } & \multicolumn{5}{|c|}{ Reason for consult } & \multirow[b]{2}{*}{ Total } \\
\hline & Accident (nontraffic) & Aggression & Self-harm & Common illness & Traffic accident & \\
\hline \multicolumn{7}{|l|}{$\mathrm{NO}$} \\
\hline \multirow{2}{*}{2000} & 43 & 14 & 15 & 138 & 62 & 272 \\
\hline & $15.8 \%$ & $5.1 \%$ & $5.5 \%$ & $50.7 \%$ & $22.8 \%$ & $100.0 \%$ \\
\hline \multirow{2}{*}{2010} & 43 & 25 & 7 & 166 & 29 & 270 \\
\hline & $15.9 \%$ & $9.3 \%$ & $2.6 \%$ & $61.5 \%$ & $10.7 \%$ & $100.0 \%$ \\
\hline \multicolumn{7}{|l|}{ SI } \\
\hline \multirow{2}{*}{2000} & 8 & 4 & 66 & 64 & 1 & 143 \\
\hline & $5.6 \%$ & $2.8 \%$ & $46.2 \%$ & $44.8 \%$ & $0.7 \%$ & $100.0 \%$ \\
\hline \multirow{2}{*}{2010} & 8 & 0 & 93 & 81 & 0 & 182 \\
\hline & $4.4 \%$ & $0.0 \%$ & $51.1 \%$ & $44.5 \%$ & $0.0 \%$ & $100.0 \%$ \\
\hline
\end{tabular}

self-harm aggression were less frequent and with no significant differences between the two groups.

3.5. Clinical Management. As for referrals of patients at the time of discharge to specific healthcare facilities specializing in drug addiction or mental health and their relation with their drug abuse record, psychiatric record, psychiatric diagnosis, and reasons for consultation in the years 2000 and 2010, we did not find significant statistical differences. On the whole, half of the patients with a record of exclusive consumption of drugs 51.1\% (96), 47.2\% (137) with a psychiatric record including drug abuse, and $46 \%$ (138) with a psychiatric diagnosis were correctly referred in the year 2000. Similar results were recorded in the year 2010 with $48.9 \%$ (92), 52.8\% (153), and 54\% (162), respectively.

According to reasons for consultation, percentages notably increased in the year 2010, when patients turned up due to common illness 81 (55.9\%) and attempted suicide 93 (58.5\%), compared to $64(44.1 \%)$ and $66(41.5 \%)$, respectively, in the year 2000. The rest of the reasons for consultation did not vary (Table 6).

\section{Discussion}

From the analysis of the results, it can be seen that the clinical profile of patients arriving to the ED with an unhealthy use of alcohol or drugs of abuse has not changed substantially after 10 years. Patients arriving due to psychiatric disorders or those of level of consciousness are the best candidates for requiring toxicological tests, but the most surprising thing is that half of them are not referred to specialized centers despite having serious drug or psychiatric records. Most of those coming due to other medical or surgical complications are simply not referred. The healthcare professional tends to treat the acute complication caused by an acute consumption of the drug or the secondary and indirect organic complications but not the addiction that makes the patient recur or cause a progressive deterioration. This attitude, the wide variety of professionals working at EDs, the lack of time, and the reluctance on the part of the patient all mean that many patients are not diagnosed in spite of the large number of patients visiting the EDs. This would explain the relatively low figures of patients showing positive in toxicological tests if we compare them with the studies carried out on the general population and prospective clinics $[11,12]$.

Traditionally, the profile of the user visiting the ED is a male under the age of 30, with polyconsumption of other drugs of abuse, who increases this use significantly at the weekends and nighttime. The most extensive use of alcohol, the incorporation of the female, and the greater introduction of consumption as an instrument of entertainment have probably made the day and time the patients turn up more random after 10 years [13].

According to various authors, the reasons for consultation in patients who have consumed substances and visit the ED can be classified in three groups: patients with psychiatric symptoms, patients with symptoms coming from other organs and systems, and patients with secondary trauma indirectly related to consumption [14-16]. We have classified the reasons for consultation in five groups: common illness including psychiatric illness; with the exception of attempted suicide due to its special relevance [17-20]; trauma due to traffic accident; casual accidents as a result of falls; and aggression [21]. The consumption of alcohol does not always trigger violent behavior, but many aggressors were intoxicated at the time of the aggression [22]. The higher frequency of consultation due to common illness and attempted suicide after 10 years may be related to a greater awareness on the part of doctors to order tests in patients with psychiatric symptoms or a reduction in the level of consciousness and due to the increase in the secondary suicidal behavior following an overdose of BZD with or without alcohol.

The changes shown in the specific psychiatric or neurological symptoms or those of any other nature are related with the acute consumption of alcohol and drugs but could vary according to the degree of tolerance and addiction, as well as the existence of a psychiatric record $[23,24]$. Some symptoms such as psychomotor agitation, anxiety, psychosis, headache, convulsions, stroke, or hypertensive crisis are related with drugs of a stimulant or hallucinatory effect [23-26], but others such as the reduction in the level of consciousness are more related to states of alcohol poisoning or overdose of BZD and opiates. Over the last 20 years, many studies have been published on the influence of alcohol and other drugs 
in traumatic injuries, especially TBI, at hospital EDs with a variation of between 4 and $45 \%$ depending on the population selected [10, 27-29]. The higher the intake, the greater the risk of injury [30], alcohol, BZD, cannabis, and cocaine being the drugs most detected [31]. Other symptoms secondary to the damage in other organs are not very frequent, probably due to the doctor's lack of interest to order tests. The differences of isolated symptoms are not very significant and are difficult to interpret for being a retrospective study.

Although with a high frequency, there are no significant differences in the psychiatric records of abusive consumption of drugs and psychiatric diagnosis between the 2000 group and the 2010 group. It is debatable if psychiatric diagnosis is secondary to consumption, but in any case an appropriate monitoring of the patient is required.

Alcohol, BZD, and cocaine are the drugs most frequently detected, with a significant increase being observed in BZD and cannabis, as well as the combination of alcohol and other drugs after 10 years. An increase in BZD consumption has been recently registered and has been suggested as being secondary to the greater demand for anxiety, and an increase in self-consumption due to easy access [12]. The increase in the combination of alcohol and BZD or of alcohol and cocaine and cannabis has been related to the higher incidence of attempted suicide [32, 33] and with recreational and leisure factors [11]. The consumption of methadone above the prescription dose is not very frequent, but it is noteworthy that half of these patients also consumed other opiates and nearly all BZD. It has been recently described that patients receiving chronic methadone treatment also consumed other opiates and BZD to relieve anxiety [34].

The management and referral of patients from EDs to centers specializing in drug addiction or mental health are fundamental to avoid relapses and establish a definitive treatment $[3,35,36]$. The Project ASSERT model is a low cost, effective program offering screening, brief intervention, and referral to treatment services for ED patients with unhealthy alcohol and drug use that can be successfully integrated into the clinical setting. It also offers an innovative strategy for reducing the gap between substance abuse needs of emergency patients and services [35]. Our results show that nearly half of the patients with a record of consumption, psychiatric illness, or psychiatric diagnosis were not correctly referred. The doctor in the ED tends to order tests for patients with determined symptoms but later does not refer them adequately. Others, with other symptoms or traumatic injuries, simply do not refer them or are probably not diagnosed. It is our responsibility that patients with alcohol and drug dependence receive a facilitated referral and are linked directly with a specialized center likely to enroll in a treatment program.

After 10 years, we found that patients with substance abuse problems present with higher incidence of self-harm and comorbid psychiatric symptoms. Some of these patients may be referred to psychiatric units rather than specialized substance abuse units. These could have affected our results. As compared to the United States, in countries with socialized medicine despite the recent financial crisis, the number of available beds for substance abuse treatment has remained relatively stable. We believe that in these settings, still, one of the major barriers for referral to specialized substance abuse centers is the lack of training in this matter rather than lack of centers for treatment.

This study however has some limitations. The study was carried out at a third-level University Hospital and the patient characteristics and treatment style of this specific teaching hospital may differ with other hospitals, which makes it difficult to generalise the findings of this study. Due to that, our results should be taken with caution.

In conclusion, the clinical profile of the patient visiting the ED with symptoms of alcohol and drugs of abuse has not clearly changed after a decade. The professionals order these tests, mainly if they show psychiatric symptoms or those of level of consciousness, but many are not referred, and in the rest of patients, they may be not even diagnosed. The implementation of simple programs for detection and referral of these patients from the ED is essential and urgent.

\section{Conflict of Interests}

The authors declare no conflict of interests with this paper.

\section{References}

[1] C. J. Cherpitel and Y. Ye, "Trends in alcohol- and drug-related emergency department and primary care visits: data from four U.S. national surveys (1995-2010)," Journal of Studies on Alcohol and Drugs, vol. 73, no. 3, pp. 454-458, 2012.

[2] M. Fendrich, T. P. Johnson, J. S. Wislar, A. Hubbell, and V. Spiehler, "The utility of drug testing in epidemiological research: results from a general population survey," Addiction, vol. 99, no. 2, pp. 197-208, 2004.

[3] B. K. Madras, W. M. Compton, D. Avula, T. Stegbauer, J. B. Stein, and H. W. Clark, "Screening, Brief Interventions, Referral to Treatment (SBIRT) for illicit drug and alcohol use at multiple healthcare sites: comparison at intake and 6 months later," Drug and Alcohol Dependence, vol. 99, no. 1-3, pp. 280-295, 2009.

[4] J. Grundlingh, "The use of urine drugs of abuse screens in emergency departments best bets," Screening for the substance abuse in the Emergency Room, http://bestbets.org/bets/bet.php?id= 2185, 2011.

[5] F. Escobar, F. Espi, and M. Canteras, "Problems related to alcohol consumption in primary health care: prevalence and clinical profile," Family Practice, vol. 10, no. 4, pp. 424-430, 1993.

[6] F. Espi and S. Conde, "Prevalencia de alcoholismo en un Hospital Universitario," in Manual de Estudios Sobre Alcohol, pp. 245-299, EDAF, Madrid, Spain, 2001.

[7] P. A. Calle, J. Damen, P. De Paepe, K. G. Monsieurs, and W. A. Buylaert, "A survey on alcohol and illicit drug abuse among emergency department patients," Acta Clinica Belgica, vol. 61, no. 4, pp. 188-195, 2006.

[8] F. Espi Martinez, J. Nieto, and F. Espi Forcen, "Screening for the substance abuse in the emergency room," The American Journal on Addictions, vol. 21, pp. 388-389, 2012.

[9] J. S. Eisen, M. L. A. Sivicotti, K. U. Boyd et al., "Screening urine for drugs of abuse in the emergency department: Do test result affect physicians'patient care decisions?" Canadian Journal of Emergency Medicine, vol. 6, no. 2, pp. 104-111, 2004.

[10] B. Taylor, H. M. Irving, F. Kanteres et al., "The more you drink, the harder you fall: a systematic review and meta-analysis of 
how acute alcohol consumption and injury or collision risk increase together," Drug and Alcohol Dependence, vol. 110, no. 1-2, pp. 108-116, 2010.

[11] E. Sanjurgo, M. Camara, S. Nogué et al., "Urgencias por consumo de drogas de abuso: confrontación entre los datos clínicos y analíticos," Emergencias, vol. 17, pp. 26-31, 2005.

[12] Informe n¹1, Observatorio Español de la Droga y Toxicomanías. Situación y Tendencias de Los Problemas de Drogas en España, Ministerio del Interior, 2011.

[13] K. Hughes, M. A. Bellis, A. Calafat et al., "Substance use, violence, and unintentional injury in young holidaymakers visiting Mediterranean destinations," Journal of Travel Medicine, vol. 18, no. 2, pp. 80-89, 2011.

[14] C. J. Cherpitel and Y. Ye, "Drug use and problem drinking associated with primary care and emergency room utilization in the US general population: data from the 2005 national alcohol survey," Drug and Alcohol Dependence, vol. 97, no. 3, pp. 226230, 2008.

[15] C. J. Cherpitel, J. Bond, Y. Ye, G. Borges, S. Macdonald, and N. Giesbrecht, "A cross-national meta-analysis of alcohol and injury: data from the Emergency Room Collaborative Alcohol Analysis Project (ERCAAP)," Addiction, vol. 98, no. 9, pp. 12771286, 2003.

[16] S. G. Vitale, D. Van De Mheen, A. Van De Wiel, and H. F. L. Garretsen, "Alcohol and illicit drug use among emergency room patients in The Netherlands," Alcohol and Alcoholism, vol. 41, no. 5, pp. 553-559, 2006.

[17] I. Rossow and A. Amundsen, "Alcohol abuse and suicide: a 40year prospective study of Norwegian conscripts," Addiction, vol. 90, no. 5, pp. 685-691, 1995.

[18] R. C. Kessler, G. Borges, and E. E. Walters, "Prevalence of and risk factors for lifetime suicide attempts in the National Comorbidity Survey," Archives of General Psychiatry, vol. 56, no. 7, pp. 617-626, 1999.

[19] A. Roy, "Characteristics of cocaine-dependent patients who attempt suicide," The American Journal of Psychiatry, vol. 158, no. 8, pp. 1215-1219, 2001.

[20] A. Oster, S. Bernbaum, and S. Patten, "Determinants of violence in the psychiatric emergency service," Canadian Medical Association Journal, vol. 164, no. 1, pp. 29-34, 2001.

[21] C. Heung, J. Lemar, and B. Rempel, "Alcohol and communitybased violence: a review of evidence and control policies," Clinical Review, vol. 8, no. 1, pp. 32-33, 2011.

[22] G. M. Curran, G. Sullivan, K. Williams et al., "Emergency department use of persons with comorbid psychiatric and substance abuse disorders," Annals of Emergency Medicine, vol. 41, no. 5, pp. 659-667, 2003.

[23] M. Reynaud, R. Schwan, M. N. Loiseaux-Meunier, P. Albuisson, and E. Deteix, "Patients admitted to emergency services for drunkenness: moderate alcohol users or harmful drinkers?" The American Journal of Psychiatry, vol. 158, no. 1, pp. 96-99, 2001.

[24] J. Neiman, H. M. Haapaniemi, and M. Hillbom, "Neurological complications of drug abuse: pathophysiological mechanisms," European Journal of Neurology, vol. 7, no. 6, pp. 595-606, 2000.

[25] R. Pavarin, F. Lugoboni, S. Mathewson, A. M. Ferrari, G. Guizzardi, and G. Quaglio, "Cocaine-related medical and trauma problems: a consecutive series of 743 patients from a multicentre study in Italy," European Journal of Emergency Medicine, vol. 18, no. 4, pp. 208-214, 2011.

[26] M. P. Charalambous, "Alcohol and the accident and emergency department: a current review," Alcohol and Alcoholism, vol. 37, no. 4, pp. 307-312, 2002.
[27] S. Vitale and D. Van De Mheen, "Illicit drug use and injuries: a review of emergency room studies," Drug and Alcohol Dependence, vol. 82, no. 1, pp. 1-9, 2006.

[28] G. Ricci, S. Majori, W. Mantovani, A. Zappaterra, G. Rocca, and F. Buonocore, "Prevalence of alcohol and drugs in urine of patients involved in road accidents," Journal of Preventive Medicine and Hygiene, vol. 49, no. 2, pp. 89-95, 2008.

[29] M. Harr, B. Heskestad, T. Ingebrigtsen, B. Romner, P. Ronning, and E. Helseth, "Alcohol consumption, blood alcohol concentration level and guideline compliance in hospital referred patients with minimal, mild and moderate head injuries," Scandinavian Journal of Trauma, Resuscitation and Emergency Medicine, vol. 19, pp. 25-28, 2011.

[30] S. T. Bogstrand, P. T. Normann, I. Rossow, M. Larsen, J. Mørland, and $\varnothing$. Ekeberg, "Prevalence of alcohol and other substances of abuse among injured patients in a Norwegian emergency department," Drug and Alcohol Dependence, vol. 117, no. 2-3, pp. 132-138, 2011.

[31] M. C. Mauri, G. Cerveri, L. S. Volonteri et al., "Parasuicide and drug self-poisoning: analysis of the epidemiological and clinical variables of the patients admitted to the Poisoning Treatment Centre (CAV), Niguarda General Hospital, Milan," Clinical Practice and Epidemiology in Mental Health, vol. 1, pp. 5-11, 2005.

[32] E. J. M. Pennings, A. P. Leccese, and F. A. De Wolff, "Effects of concurrent use of alcohol and cocaine," Addiction, vol. 97, no. 7, pp. 773-783, 2002.

[33] H. G. Fulton, T. Barrett, C. MacIsaac, and S. H. Stewart, "The relationship between self-reported substance use and psychiatric symptoms in low-threshold methadone maintenance treatment clients," Harm Reduction Journal, vol. 8, pp. 18-23, 2011.

[34] R. M. Cunningham, E. Bermstein, M. Walton et al., "Alcohol, tobacco, and other drugs: future directions for screening and intervention, and referral to treatment program for unhealthy alcohol and drug use into an urban emergency department," Academic Emergency Medicine, vol. 16, no. 11, pp. 1078-1088, 2009.

[35] G. D’onofrio and L. C. Degutis, "Integrating project ASSERT: a screening, intervention, and referral to treatment program for unhealthy alcohol and drug use into an urban emergency department," Academic Emergency Medicine, vol. 17, no. 8, pp. 903-911, 2010.

[36] F. C. Blow, M. A. Walton, R. Murray et al., "Intervention attendance among emergency department patients with alcohol-and drug-use disorders," Journal of Studies on Alcohol and Drugs, vol. 71, no. 5, pp. 713-719, 2010. 


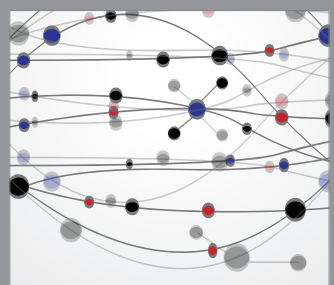

The Scientific World Journal
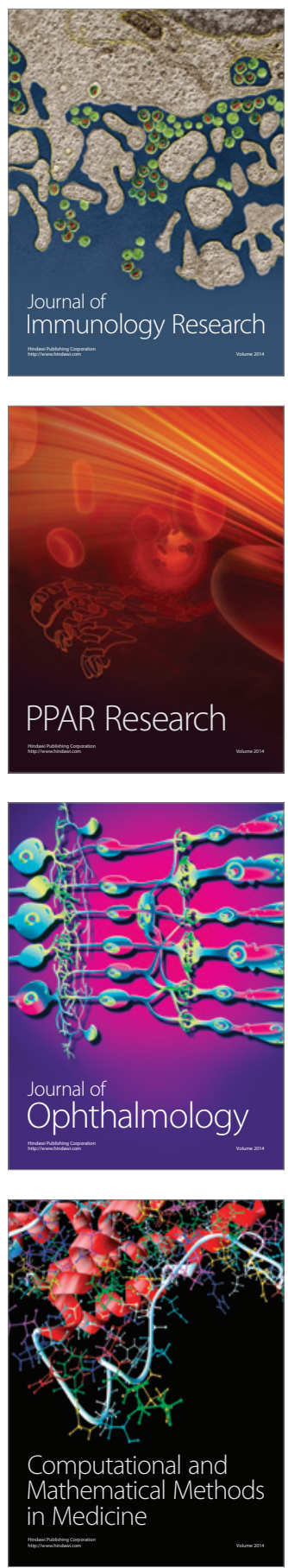



Gastroenterology

Research and Practice


\section{Hindawi}

Submit your manuscripts at

http://www.hindawi.com
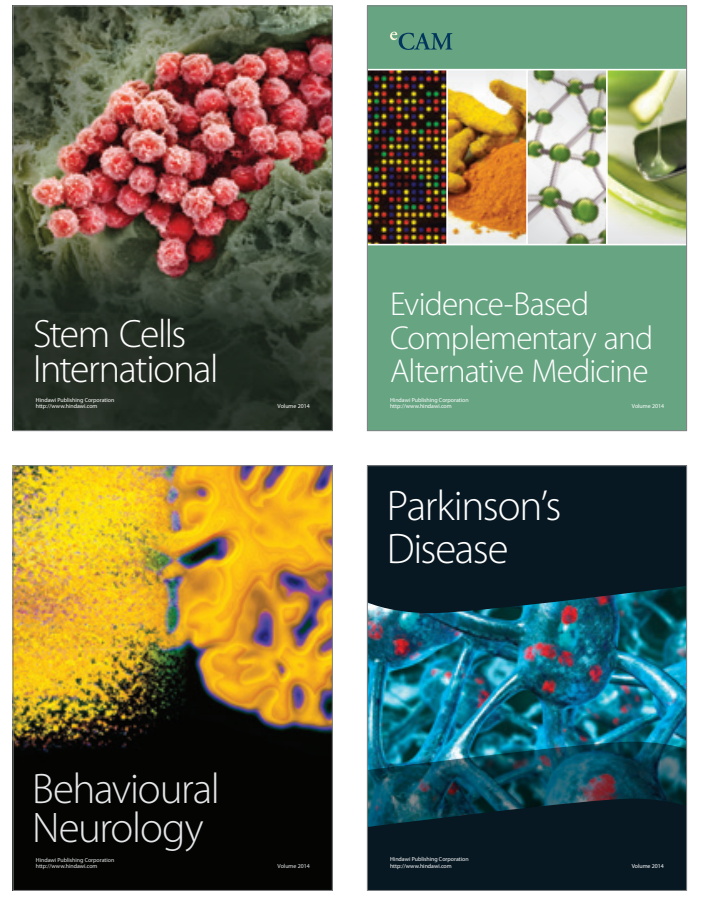
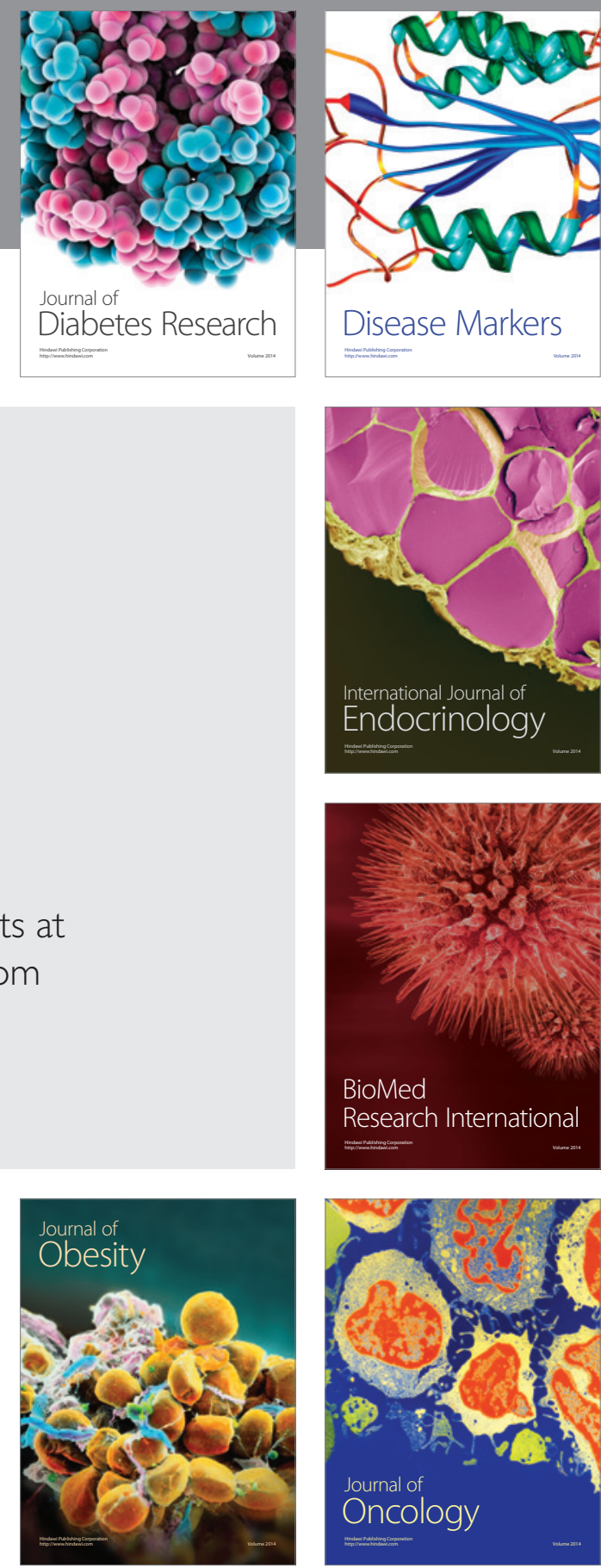

Disease Markers
